Journal of

Health, Medicine and Nursing

(JHMN)

DETERMINANTS OF HOME BIRTHS AMONG WOMEN OF REPRODUCTIVE AGE AFTER ANTENATAL HOSPITAL CARE VISITS IN NAROK COUNTY, KENYA

Purity Ngotiek, Dr. Titus Muhu Kahiga and Dr. Onyambu Meshack Ondora

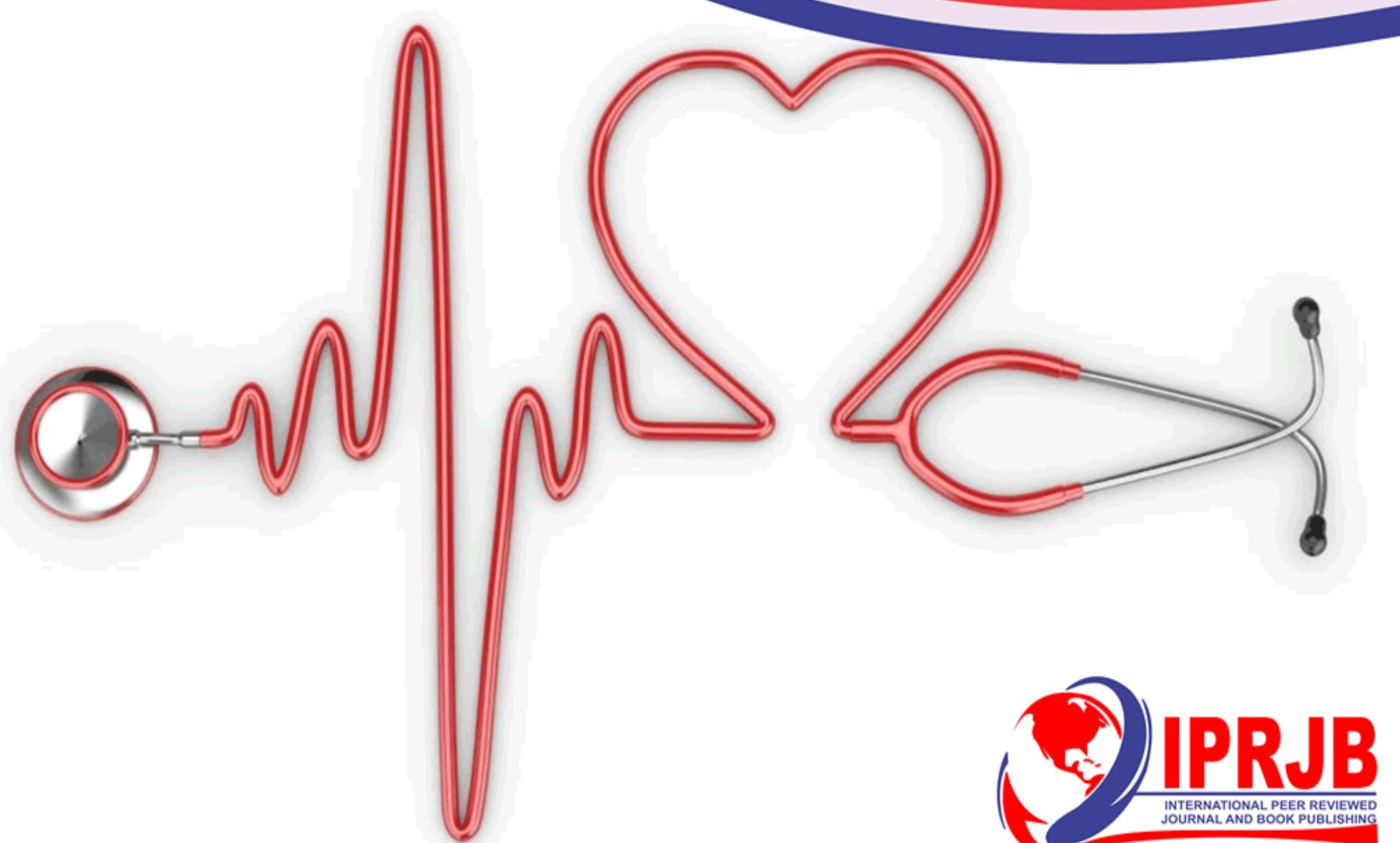


Journal of Health, Medicine and Nursing

ISSN 2520-4025 (Online)

Vol.7, Issue 3. No.2, pp 10- 28, 2021

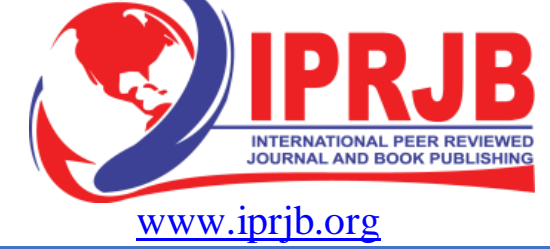

\title{
DETERMINANTS OF HOME BIRTHS AMONG WOMEN OF REPRODUCTIVE AGE AFTER ANTENATAL HOSPITAL CARE VISITS IN NAROK COUNTY, KENYA
}

\author{
${ }^{1 *}$ Purity Ngotiek \\ ${ }^{1}$ Post Graduate Student: Public Reproductive Health, Kenyatta University \\ *Corresponding Author's E-mail: pngotiek@gmail.com \\ ${ }^{2}$ Dr. Titus Muhu Kahiga \\ Lecturer: Department; Pharmacology and Clinical Pharmacy Kenyatta University \\ ${ }^{3}$ Dr. Onyambu Meshack Ondora \\ Lecturer: Department of Pharmacognosy, Pharmaceutical Chemistry and Pharmaceutics, and \\ Industrial Pharmacy. Kenyatta University
}

\begin{abstract}
Purpose: The purpose of the study was to investigate the contributors associated with having a home delivery after antenatal hospital care visits in women of reproductive age in Narok South Sub-County, Kenya.

Materials and Methods: Across-sectional survey of 323 women who delivered at home within the last two years yet attended antenatal care clinics was carried out. The survey was conducted in Narok south sub-county, and respondents were picked randomly from all the wards. Data was collected using an interviewer-administered questionnaire; exploration of variables was done using a chi-squire test. Using odd ratio with95\% confidence interval with $\mathrm{p}<0.05$ taken as a statistically significant association.

Results: The One way ANOVA analysis indicated that there was a significant influence on source of income and home delivery $(\mathrm{F}=62.022, \mathrm{P}=0.0001$. All three factors (age, education, distance) had a significant positive relationship with the number of children delivered at home( $\mathrm{r}$ $=0.574,0.677$ and 0.534 respectively). Using Pearson correlation analysis, the findings revealed that the distance to the health facility significantly influenced home delivery $(\mathrm{r}=0.53$, $\mathrm{P}=0.0001)$.On assessing the level of knowledge associated with home delivery, many mothers were aware of bleeding and perinea tears as complications. Given opportunity majority would not deliver at home again (77.4\%). Those who had no emergency backup plan were96.3\% and those who stated that they would deliver at home again, had no emergency backup plan. In contrast, women who had emergency backup plans would not deliver at home again (Fishers' exact test $=3.628, \mathrm{P}=0.043$ ). Awareness of the risk factors stated $95.0 \%$ were aware of the risk of placenta praevia and bleeding problems, and there was no significant difference in the number of women aware of the danger signs to those not familiar (x2 value 30000,p-value 0.224).
\end{abstract}

Unique contribution to theory, practice and policy: The study recommended that the County Education officers in liaison with social development officers should promote adult formal education to improve literacy levels, which will go a long way in influencing reproductive health decisions. County health management team, together with the reproductive health section should network with other relevant stakeholders to increase sensitization on utilization of hospital-based deliveries.

Key words: Home Delivery, Antenatal Hospital Care, Reproductive Age 
Journal of Health, Medicine and Nursing

ISSN 2520-4025 (Online)

Vol.7, Issue 3. No.2, pp 10- 28, 2021

\subsection{INTRODUCTION}

Maternal fine fettle is the stability of women during prenatal period, labor, childbirth, and the afterbirth period. When a woman gives birth, her life is at stake and worse when a woman delivers at home, creating a major concern for public health. Giving birth at home accelerates maternal mortality and many other complications, which greatly affects the health of a woman and that of the newborn baby. Despite its obvious health-related problems, including maternal morbidity and mortality, many women still do not seek professional health care services when giving birth. In Kenya, the proportion of home deliveries seems to increase despite interventions by the government, international development partners, and non-governmental organizations to discourage home births (Atupamoi, 2017). Skilled assistance during childbirth is core to bringing down maternal mortality; however, the number of deliveries in hospital settings where professionalism can reliably be provided has remained below 50\% since the early 90s (KDHS, 2014). While the global target to reduce home-based delivery mortality is $75 \%$ globally, there has been a decline of $43 \%$ in Africa and only $18 \%$ in Kenya (Oriento, 2014).

In the Africa Progress Panel Policy Brief (2010), a high proportion of women in developing countries still give birth at home unattended by skilled health care workers and more so in a patriarchal community like the Maasai where decision making does not involve women. Some of the major factors associated with giving birth at home have been identified as maternal age (many teenage and young mothers tend to give birth at home), parity (This is the number of children a woman has), level of education, and marital status. Community factors that contribute to home delivery include socio-economic status and community health infrastructures which are very significant in reduction of non-facility-based deliveries. Some of the major health complications associated with home deliveries includes sepsis, uterine rapture, obstructed labor, excessive hemorrhage, and retention of products of conception. Major causes of maternal mortality mostly occurring due to home births are obstructed labor, unsafe abortion, hemorrhage, anemia, and sepsis (Shipmate al., 2013).

As the health sector strives to achieve sustainable development goal (SDG) for maternal health, of utmost urgency is to develop interventions to achieve them and reduce deaths related to childbearing and improve greatly on their health during the child birthing process. The ability of a woman to be safe and healthy during gestational period and child birth is very important in ensuring a reduction in maternal mortality and morbidity as well as neonatal mortality. Having a delivery under the supervision of a trained health care provider is focal in all these. Safe parenthood necessitates that all women can get a full scope of high caliber reproductive health services, more so maternal care, treatment of obstetric conditions and emergencies with the sole aim of reducing death and disabilities associated with pregnancy and giving birth. Access to safe, affordable, and appropriate reproductive health services is a human right and must be pinned down by laws and policies (Moindi, 2016).

In the Maasai community, child birth is a social affair, passionate occasion, and fundamental piece of family life. It involves the whole of the extended family to take the woman through pregnancy, child birth, and the first few months after birth. Social and cultural issues play a great role during this period. There is value in the customs and rituals encompassing giving birth. In keeping these as a focal element of family life, a woman sometimes is forced to give birth at home to pave the way for cultural practices and a sense of belonging to the family unaware of the hazardous effects on the mother's health (Nganyo, Torud, Kvale, Byskor, Bjorg, Michelo, Echoka \& Knut, 2014). 
Journal of Health, Medicine and Nursing

ISSN 2520-4025 (Online)

Vol.7, Issue 3. No.2, pp 10- 28, 2021

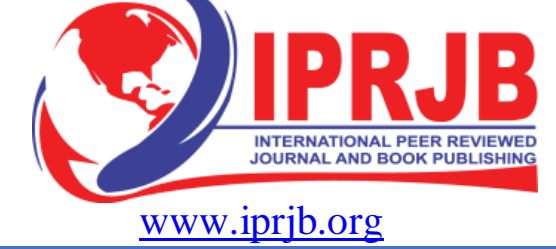

Early identification of pregnancy and any complications related to prenatal period, labor, and child birth access to a skilled health professional when giving birth is very crucial in prevention and management of complications of child birth, skilled medical care during birthing, and immediate afterbirth adverse effects management for both mother and baby can greatly bring down maternal and new born morbidity and mortality (Njuguna, Njoroge and Muruka, 2017). However, few African states Kenya included have structures in place to certify that both women and their infants are assed during pregnancy, bearing, and postnatal aeon. Data indicate that there are important occasions when attended to in a formal health system during delivery and afterbirth period by skilled attendant could be advantageous in examining and act in response to necessities and complexities likely to arise in the course of labor and after birth (Koskei et al., 2008).

Despite the fact that over $90 \%$ of Kenyan women get antenatal care services, less than half of the deliveries occur within a health facility conducted by a professional health care provider (Kingoo, 2015). In a study done by (Caulfield et al.,2016) in Laikipia and Samburu counties, conventional hospitals provide various essential duties counting maternal and child health care. Conversely, a huge part of women (92\%) still give birth in a non hospital set up with the assistance of an ill-equipped individual, a relative, or unattended by anybody. This is considerably superior to the Kenyan national average of $56 \%$ and $66 \%$ for the Rift Valley province. Understanding the determinants of home births after ANC visits requires assessing the individual, family, and community and any other factor that influences care-seeking.

Evidence from many studies globally has disclosed a decrease in maternal and prenatal loss of being when women have contact with a skilled birth caregiver who provides a constancy of care beginning at pre-conception, gestation, delivery, and during post-delivery period (Wanyuaet al., 2014). Many aspects are affiliated to women attending antenatal care in a health facility yet still prefer having a home delivery. In Kenya, the government offers free maternity services in all government facilities, implemented the WHO guidelines on ANC visits, but despite these efforts, home delivery among the community of Narok county is still very high and appears to be increasing, a fact that greatly undermines government and other health player's attempt to advance maternal wellbeing in the country. Data shows that home deliveries are still taking place even after most of these women have gone to antenatal care visits at the health facilities hence the need to find out why the women prefer to deliver at home even after attending ANC in formal health setups. The goal of this study was, to identify the main drivers of home-based child delivery among reproductive-age women in Narok county, estimating the level of knowledge on risks of home delivery, to investigate influential factors to place of delivery for women in Narok South Sub-County, and the socio-demographic, economic and cultural characteristics of these women.

\subsection{Problem Statement}

Maternal well-being isn't just required to provide humanitarian tranquility and financial productivity. In addition, it cuts down costs and excess baggage on relatives, communities, specialists in health and specifically reproductive wellbeing, and the national treasury. In Narok County alone, data collected from 30 health facilities showed a $67 \%$ increase in women seeking ANC services in a health care facility between the year 2013 and 2015 (from 6,187 in 2013 to 10,326 in 2015) (Personal observations, Narok County Hospital Department of health records management 2016). The number of births attended by a professional health care provider in Narok County went up from 9,370 in 2013 to 14,486 in 2015 (an overall increase in the proportion of births attended by a skilled health provider from $20.1 \%$ in 2013 to $34.8 \%$ in 2015), 
Journal of Health, Medicine and Nursing

ISSN 2520-4025 (Online)

Vol.7, Issue 3. No.2, pp 10- 28, 2021

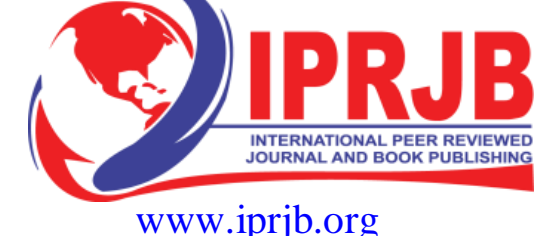

these are according to the county health information system. December 2018, 7,604 women went for ANC services, 2,277 only delivered in a hospital set up and 5,327 delivered in a non-hospital setup. Therefore, the researcher investigated why more than half of women of reproductive age in Narok South sub-county prefer to deliver at home after antenatal care visits. With the above figures compared to the population of Narok county of over one million, it is evident that despite the increase in utilization of health services during child birth still many women are giving birth at home; hence a survey was carried out to find out why there is still poor usage of health facility delivery amid reproductive age women of Narok county.

When the health of a woman is compromised, the whole family is at a health risk because she cannot take good care of her family, make proper and timely decisions, support her family financially and be there for them; this creates a life cycle of poverty from one generation to another which began from an incidence of child birth which is very preventable when health facilities are utilized during that crucial moment of child birth.

\subsection{LITERATURE REVIEW}

\subsection{Theoretical Review}

\section{SOCIAL COGNITIVE THEORY}

Social cognitive theory by Bandura proposes that human behavior is driven by inner forces and external influences. It further explains human behavior in three dimensions: particular components, surrounding influences, and behavior regularly interacting to produce an action. A basis of the social cognitive theory is that individuals learn not only through personal experiences but also from observing the actions of others and the outcome of these actions. In relation to home delivery, a woman who consciously decides to deliver at home could be controlled by personal factors such as experiences during previous births and environmental influences such as cultural-economic influence and infrastructure of that locality.

\subsection{Conceptual Framework}

Conceptual framework is a tool which provides variational analysis linked to the research's goal. In this study the conceptual framework to be used is presented in Figure 1. 
Journal of Health, Medicine and Nursing

ISSN 2520-4025 (Online)

Vol.7, Issue 3. No.2, pp 10- 28, 2021

\section{INDEPENDENT VARIABLES}

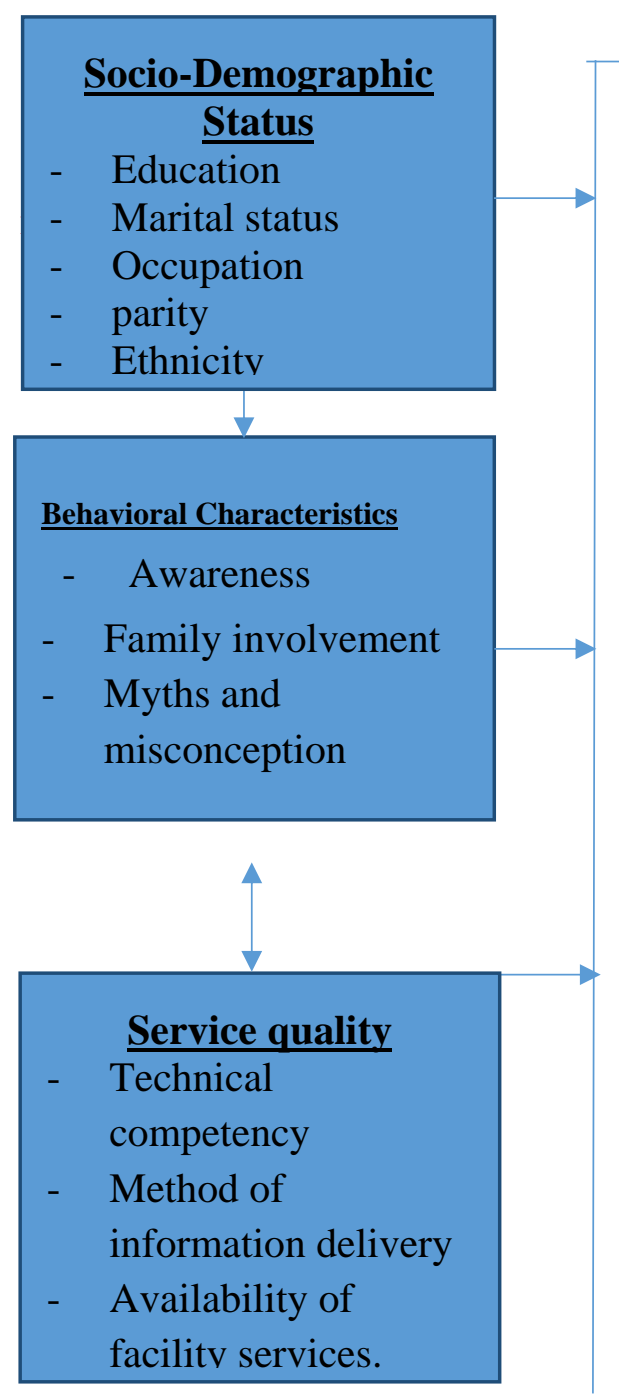

\section{DEPENDENT VARIABLE}

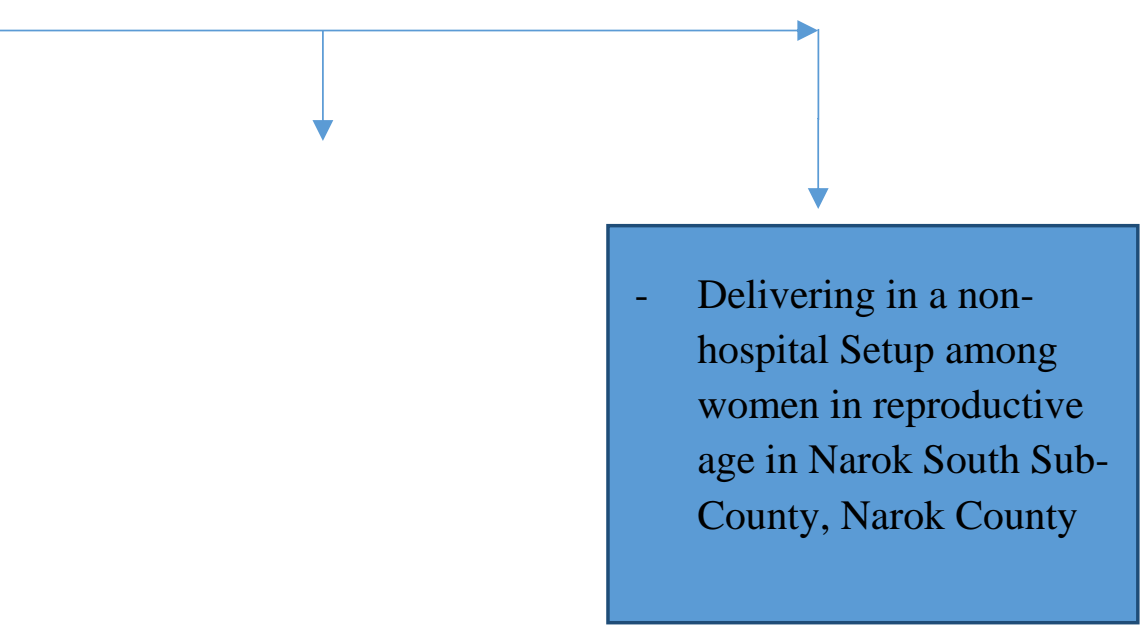

Conceptual Frame work (Imenda, 2014).

\subsection{METHODOLOGY}

Across-sectional survey of 323 women who delivered at home within the last two years yet attended antenatal care clinics was carried out. The survey was conducted in Narok south subcounty, and respondents were picked randomly from all the wards. The study utilized primary data only. The primary data was collected through semi structured questionnaires by visiting households with women of reproductive age who gave birth in the last 24 months in a nonhospital set up. Data was analyzed using excel and statistical package for social sciences SPSS version22.0. Descriptive statistics involved the application of percentages and frequencies. Inferential statistics and regression analysis also involved the utilization of chi-squire and Pearson correlation coefficients. Results were exhibited in type of tables and correlation matrices. The level of confidence was at $95 \%$. 
Journal of Health, Medicine and Nursing

ISSN 2520-4025 (Online)

Vol.7, Issue 3. No.2, pp 10- 28, 2021

\subsection{RESULTS}

\subsection{Demographic information of the women}

The majority of the respondents $(62.5 \%)$ were married. Single women were $16.1 \%$ only. Looking at the highest levels of their education, the result indicated that majority $(69.3 \%)$ of these women had no formal education. However, three $(0.9 \%)$ of the women had a college level of education. The women's level of education and marital status had a significant effect on giving birth at home $(\mathrm{P}<0.05)$, as shown in table 1.

Table 1: Demographic information of the respondents

\begin{tabular}{llccc}
\hline Demographic & Category & $\begin{array}{l}\text { No. of women } \\
(\mathbf{n = 3 2 3})\end{array}$ & Percent & $\begin{array}{l}\text { P-value } \\
\left(\chi^{2} \text { test }\right)\end{array}$ \\
\hline Marital status & Single & 52 & 16.1 & \\
& Married & 202 & 62.5 & \\
& Divorced/Separated & 12 & 3.7 & \\
& Widowed & 57 & 17.6 & $0.0001^{*}$ \\
\hline Highest education & & & & \\
level & No formal education & 224 & 69.3 & \\
& Primary education & 54 & 16.7 & \\
& Secondary education & 42 & 13.0 & \\
& College & 3 & 0.9 & $0.0001^{*}$ \\
\hline
\end{tabular}

Table 1: Demographic information of the respondents

*indicate significance at $\mathrm{P} \leq 0.05$

\subsubsection{Religion}

Among the sampled 323 women, the dominant religion of the respondents was established to be Protestantism. The result showed that $92.9 \%$ of the respondents were Protestants. This was followed by Catholics and Muslims Figure 2.

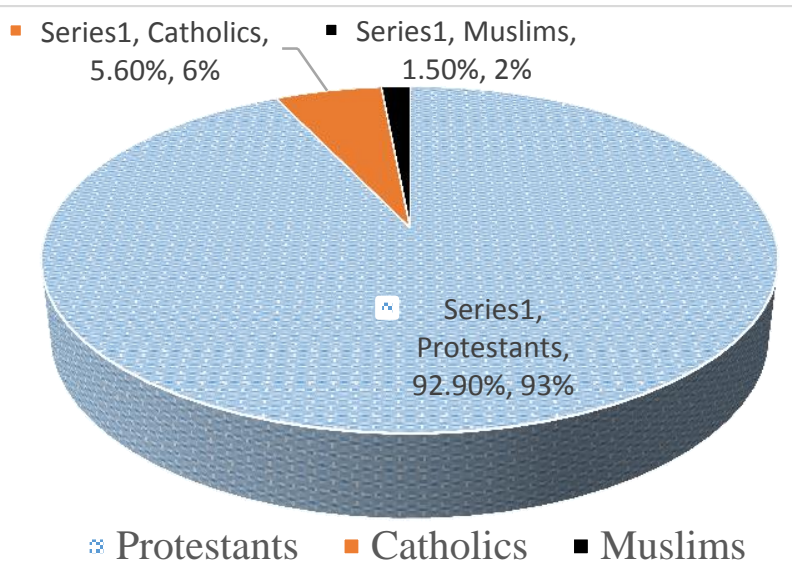

Figure 2: Distribution of the religion of the respondents 
Journal of Health, Medicine and Nursing

ISSN 2520-4025 (Online)

Vol.7, Issue 3. No.2, pp 10- 28, 2021

\subsubsection{Ethnicity}

The study respondents were from Maasai, Kalenjin, and other ethnic groups in Kenya. This study mainly focused on the Maasai community women, who accounted for $79.9 \%$ of the respondents. However, Kalenjins (10.2\%) and other ethnic groups accounted for 9.9\%. Figure 3.

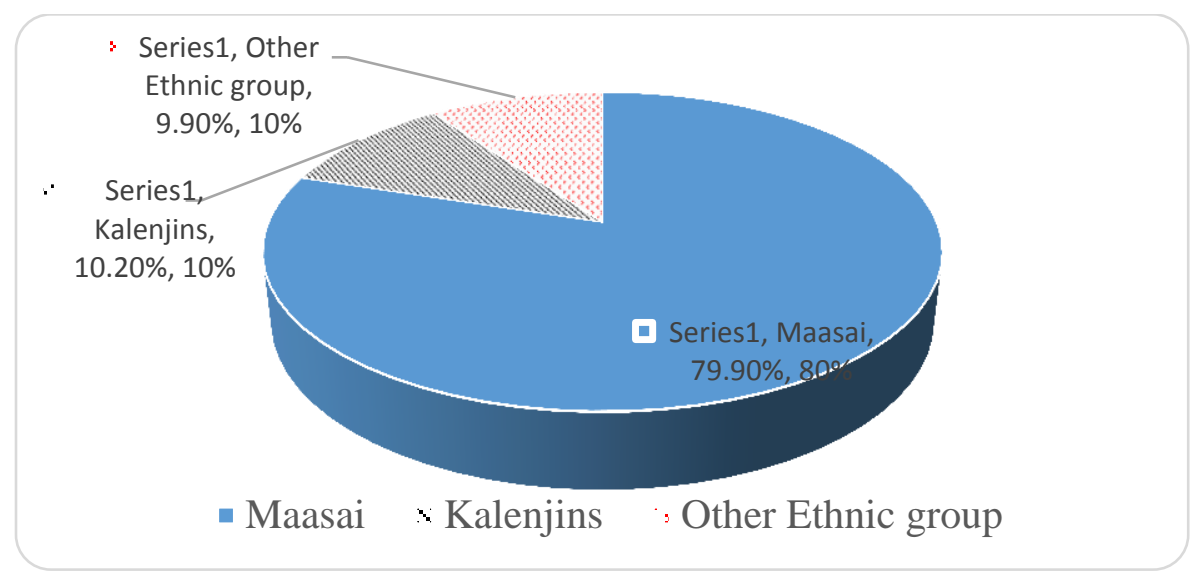

Figure 3: Ethnicity of the sampled women respondents

\subsubsection{Women primary sources of Income}

The major source of income of the respondents was self-employment. Among the sampled population, $48.3 \%$ were housewives, $26.0 \%$ were self-employed, $18.0 \%$ were unemployed, and $5.0 \%$ were Casual laborers, while $1.9 \%$ were in employment. Three of the women sampled were still students. The Source of income significantly determines the delivery at home of the women $(\mathrm{P}<0.05)$. Table 2.

Table 2: Income status of the respondents

\begin{tabular}{lccc}
\hline Status & No. of women $(\mathbf{n}=\mathbf{3 2 3})$ & Percent & $\begin{array}{c}\text { P-value }\left(\chi^{2}\right. \\
\text { test })\end{array}$ \\
\hline Casual laborer & 16 & 5.0 & \\
Employed & 6 & 1.9 & \\
Self-employed & 84 & 26.0 & \\
House wife & 156 & 48.3 & \\
Student & 3 & 0.9 & \\
Unemployed & 58 & 18.0 & 0.0001 \\
\hline
\end{tabular}

\subsubsection{Parity}

The number of times the respondents had given birth to a fetus with 24 weeks or more was established. On average, respondents in this study had a mean parity of 4.43 children-a minimum of 1 and a maximum of 11 . Considering respondents' parity by the ethnic group showed that Maasai had a parity of 4.40, Kalenjin, 4.06 while others, 5.00. Figure 4. 
Journal of Health, Medicine and Nursing

ISSN 2520-4025 (Online)

Vol.7, Issue 3. No.2, pp 10- 28, 2021

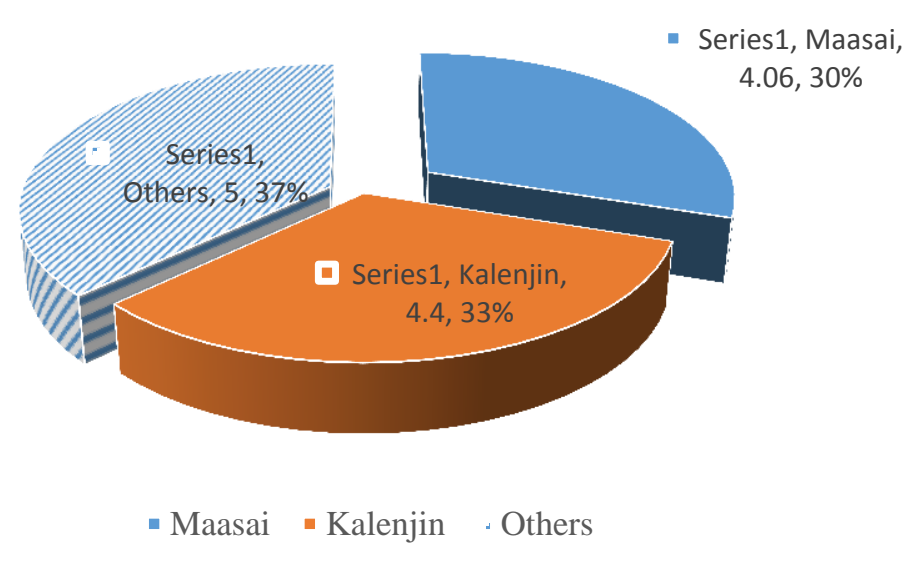

Figure 4: Parity of the respondents by ethnic group

\subsubsection{Number of children given birth at home}

The total number of children given birth at home in the sampled population was 874 . The minimum number was one child, whereas the maximum was nine children. This showed that the average number of children born at home was 2.27 children among the Maasai women, 3.76 children among the Kalenjin community, and 5.13 children among the other community. There was a significant difference in the number of children delivered at home in the ethnic groups $(\mathrm{F}=$ 154.294, $\mathrm{P}=0.0001)$. Table 3 .

Table 3: Number of children delivered at home by the ethnic groups

\begin{tabular}{|l|l|l|l|}
\hline Ethnic group & $\begin{array}{l}\text { Number of children delivered at } \\
\text { home }(\text { mean } \pm \text { SE) }\end{array}$ & F -value & P - value \\
\cline { 1 - 2 } Maasai & $2.27 \pm 0.04$ & \multirow{2}{*}{154.294} & 0.0001 \\
\cline { 1 - 2 } Kalenjin & $3.74 \pm 0.12$ & & \\
\hline Others & $5.13 \pm 0.38$ & & \\
\hline
\end{tabular}

Table 3: Number of children delivered at home by the ethnic groups

4.2 To assess the level of knowledge on risks associated with home deliveries among women of reproductive age after formal antenatal care visits in Narok South Sub- County

\subsubsection{Number of children delivered at home}

Among the respondents, the average number of children delivered at home was 2.70 ( 3 children). The minimum number was one child whereas the highest number was ten children. If given the opportunity, $77.4 \%$ of the women would not deliver at home. Figure 5. 
Journal of Health, Medicine and Nursing

ISSN 2520-4025 (Online)

Vol.7, Issue 3. No.2, pp 10- 28, 2021

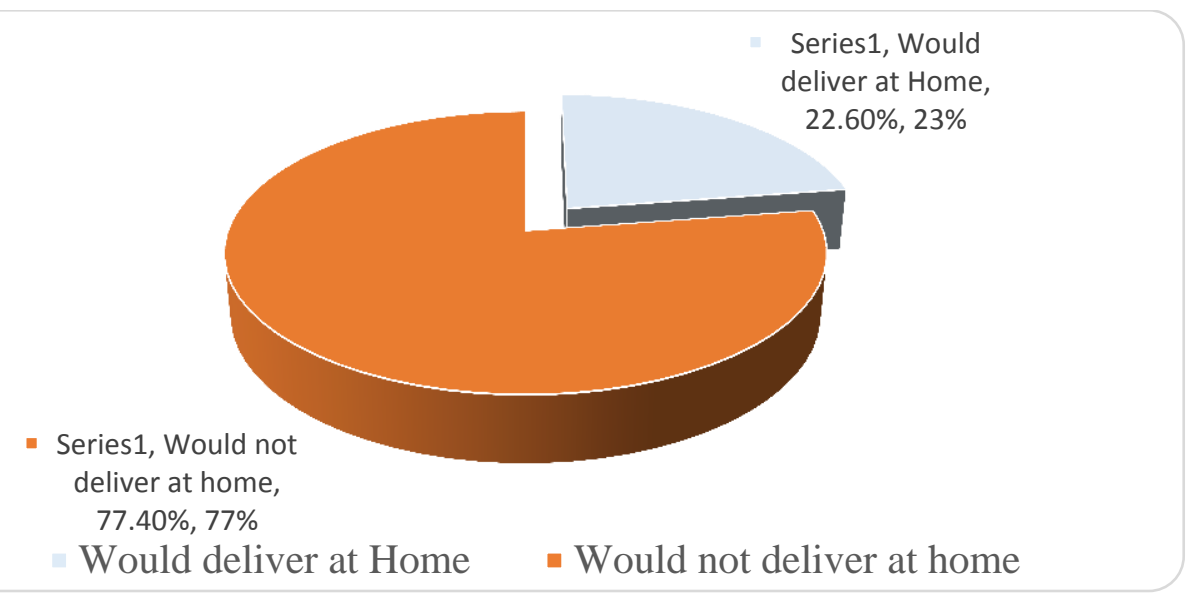

Figure 5: Women who would deliver at home again

During their last pregnancy and labor time, the majority of the women (96.3\%) had no emergency backup plan. Only $3.7 \%$ had backup plans. Those who stated that they would deliver at home again had no emergency backup plan, while women who had emergency backup plan would not deliver at home again (Fishers' exact test $=3.628, \mathrm{P}=0.043$ ). This showed a significant association between having a backup plan and a place of delivery. The findings showed that $4.8 \%$ of those who would not deliver at home again had a backup plan: table 4 .

Table 4: Association between delivering at home and having an emergency backup plan

\begin{tabular}{lccc}
\hline Delivery at home & $\begin{array}{c}\text { Had an emergency } \\
\text { backup plan }\end{array}$ & $\begin{array}{c}\text { No emergency } \\
\text { backup plan }\end{array}$ & Total \\
\hline $\begin{array}{l}\text { Would deliver } \\
\text { home again }\end{array}$ & $0(0.0 \%)$ & $73(100 \%)$ & $73(100 \%)$ \\
$\begin{array}{l}\text { Would not deliver at } \\
\text { home again }\end{array}$ & $12(4.8 \%)$ & $238(95.2 \%)$ & $250(100 \%)$ \\
$\begin{array}{l}\text { Fisher exact test } \\
\text { P value }\end{array}$ & & 3.628 & \\
\hline
\end{tabular}

\subsubsection{Risk factors during giving birth at home}

Respondents were requested to state the risk factors they are subjected to when they give birth at home. These include; excessive bleeding, fistula, abnormal pain at birth, retained placenta, and inversion of the uterus. The majority of the respondents $(95.0 \%)$ were aware of the risk of placenta praevia and bleeding problems when they give birth at home. There was no significant difference in the number of women aware of the danger signs to those not aware $(\mathrm{P}>0.05)$, as depicted in table 5 . 
Journal of Health, Medicine and Nursing

ISSN 2520-4025 (Online)

Vol.7, Issue 3. No.2, pp 10- 28, 2021

Table 5: Awareness of danger signs which can occur giving birth at home

\begin{tabular}{lcc}
\hline & \multicolumn{2}{c}{ Awareness $(\mathbf{n}=\mathbf{3 2 3})$} \\
\cline { 2 - 3 } Danger signs & Aware & Not aware \\
\hline Excessive bleeding & $291(90.1 \%)$ & $32(9.9 \%)$ \\
Fistula & $210(65.0 \%)$ & $113(35.0 \%)$ \\
Abnormal pain & $236(73.1 \%)$ & $87(26.9 \%)$ \\
Retained placenta & $227(70.3 \%)$ & $96(29.7 \%)$ \\
Placenta praevia & $307(95.0 \%)$ & $16(5.0 \%)$ \\
Inversion of the uterus & $278(86.1 \%)$ & $45(13.9 \%)$ \\
$\chi^{2}$ value & & $\mathbf{3 0 . 0 0 0}$ \\
P - value & & $\mathbf{0 . 2 2 4}$ \\
\hline
\end{tabular}

\subsubsection{Antenatal services provided}

During ANC visits, the respondents received services on IFAS (79.6\%), vaccination (98.1\%), information on HIV/AIDS $(60.1 \%)$, and birth preparedness $(60.1 \%)$. The patients reported that they visited their preferred clinics four times, and health workers answered their questions. The health service employees were available to provide their services, as stated by $79.9 \%$ of the respondents.

Table 6: Service delivery at the health facilities

\begin{tabular}{lcc}
\hline & \multicolumn{2}{c}{$\begin{array}{c}\text { Respondent opinion on services offered at } \\
\text { health facility }(\mathbf{n = 2 3 2})\end{array}$} \\
\cline { 2 - 3 } Service delivery & Yes & No \\
\hline Quality service & $257(79.6 \%)$ & $66(20.4 \%)$ \\
Received vaccination & $317(98.1 \%)$ & $6(1.9 \%)$ \\
Received information on HIV/AIDS & $194(60.1 \%)$ & $129(39.9 \%)$ \\
Birth preparedness & $194(60.1 \%)$ & $129(39.9 \%)$ \\
\hline
\end{tabular}

4.3 To investigate factors that influence place of delivery for women of reproductive age in Narok South Sub County.

\subsubsection{Factors contributing to place of delivery}

The findings revealed several factors that contribute to the place of delivery for women. These include; distance from the health facility, availability of transport to the health facility, spouse influence at home, and lack of finances. Major contributing factors were; lack of transportation at the time of delivery (31.0\%) and the notion by the respondents that delivery is not a disease $(30.0 \%)$. Merely $3.1 \%$ of the respondents gave birth at home due to their volitions. 
Journal of Health, Medicine and Nursing

ISSN 2520-4025 (Online)

Vol.7, Issue 3. No.2, pp 10- 28, 2021

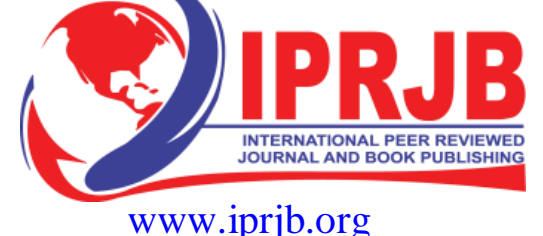

WWW.iprjb.org

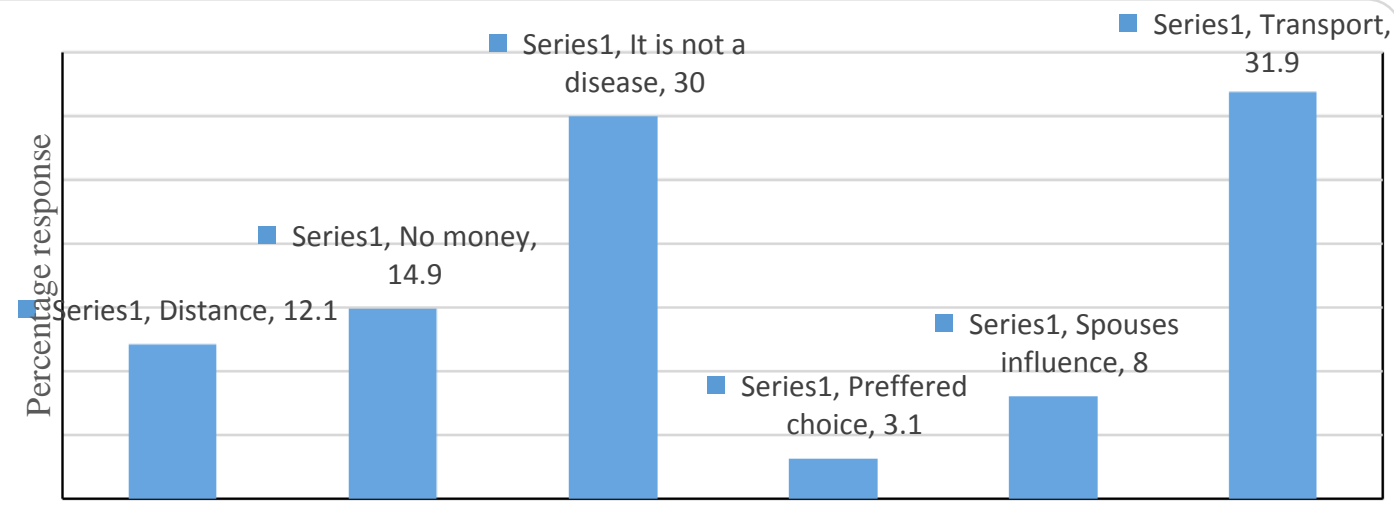

Figure 6: Factors influencing home delivery

\subsubsection{Sources of information on where to deliver}

In their choice for where to deliver, women get information from; Mothers in law, traditional birth attendants, spouses, and extended families. Main source of information is mother in law (96.0\%). This is followed by information from extended family (92.9\%). A good percentage of the respondents $(79.9 \%)$ make their own decision on where to deliver. There was a significant difference in the sources of advice $(\mathrm{t}=3.12, \mathrm{P}=0.036)$.

Table 7: Respondents source of Information on where to deliver

\begin{tabular}{lcc}
\hline Source of advice & Get advised & Not advised \\
\hline Mother in law & $310(96.0 \%)$ & $13(4.0 \%)$ \\
Traditional birth attendant & $287(88.9 \%)$ & $36(11.1 \%)$ \\
Spouse & $139(43.0 \%)$ & $184(57.0 \%)$ \\
Self & $258(79.9 \%)$ & $65(20.1 \%)$ \\
Extended family & $300(92.9 \%)$ & $23(7.1 \%)$ \\
T value & 3.12 & \\
P value & 0.036 & \\
\hline
\end{tabular}

\subsubsection{Effects of respondents' education level on delivery at home}

To establish the influence of respondents' education level on the number of children born at home, Pearson correlation analysis was carried out and tested at 95\% confidence interval. All the three factors (Age, Education, and distance) had a significant positive relationship with the number of children delivered at home $(\mathrm{r}=0.574,0.677$, and 0.534 respectively). The result indicated that elderly respondents and those staying longer distances from health facilities had a significantly higher number of children delivered at home than young persons and those living near the health facilities. 
Journal of Health, Medicine and Nursing

ISSN 2520-4025 (Online)

Vol.7, Issue 3. No.2, pp 10- 28, 2021

Www.iprjb.org

Table 8: Relationship between numbers of children delivered at home with respondents' age, education, and Distance to a health facility

\begin{tabular}{lcc}
\hline & Numbers of children delivered at home \\
\hline Respondents information & $\mathbf{r}$ - value & $\mathbf{P}$-value \\
Age of respondents & 0.574 & $0.0001^{*}$ \\
Highest Education level & 0.677 & $0.0001^{*}$ \\
Distance to a health facility & 0.534 & $0.0001^{*}$ \\
\hline
\end{tabular}

\subsubsection{Effect of the religion of the respondents on delivery at home}

The result of this study showed that the religion of the respondents had a significant effect on their choice to deliver at home. This was analyzed using One-way Analysis of Variance (Oneway ANOVA), which recorded $\mathrm{F}=0.20 .743, \mathrm{P}=0.0001$. The mean number of children delivered at home by Catholics was 1.27, Protestants, 2.75, while Muslims had a mean number of 5.00 children delivered at home.

\subsubsection{Source of Income as a factor in delivery at home}

An evaluation of individual source of income as a factor in the determination of delivery at home was carried out using one-way ANOVA. Result showed a significant influence of income on home delivery $(\mathrm{F}=62.022, \mathrm{P}=0.0001)$. Those who were employed respondents had a mean of 1.83 children delivered at home, while casual laborers had a mean of 5.75 children.

Table 9: Number of deliveries at home by respondents' different income sources

\begin{tabular}{lc} 
Source of income & $\begin{array}{c}\text { Mean number of children delivered at home } \\
\text { (mean } \pm \text { SE) }\end{array}$ \\
\hline Unemployed & $1.74 \pm 0.06 \mathrm{a}$ \\
Employed & $1.83 \pm 0.17 \mathrm{a}$ \\
Self-employed & $2.04 \pm 0.06 \mathrm{ab}$ \\
Housewife & $3.13 \pm 0.08 \mathrm{~b}$ \\
Casual laborer & $5.75 \pm 0.50 \mathrm{~d}$ \\
Student & $3.67 \pm 2.16 \mathrm{c}$ \\
\hline
\end{tabular}

Mean values denoted by similar letters are not significantly different at $\mathrm{P} \leq 0.05$. Mean separation using Tukeys HSD

\subsubsection{Influence of Ethnicity on delivery at home}

The study was mainly focused on the Maasai community however other ethnic groups were also included. These were Kalenjin (33) and others (32). Therefore, the influence of ethnicity showed that the mean number of children delivered at home by Maasai women was 2.27, Kalenjin, 3.76 while another ethnic group was 5.13. Using One-way ANOVA showed there was a significant difference in the number of children delivered at home by ethnicity $(F=154.294, P=0.0001)$.

Table 10: Number of deliveries at home by respondents' ethnic group

\begin{tabular}{lc}
\hline Ethnic group & $\begin{array}{c}\text { Mean number of children delivered at home } \\
(\text { mean } \pm \text { SE) }\end{array}$ \\
\hline Maasai & $2.27 \pm 0.04 \mathrm{a}$ \\
Kalenjin & $3.76 \pm 0.12 \mathrm{~b}$ \\
Others & $5.13 \pm 0.38 \mathrm{c}$ \\
\hline
\end{tabular}


Journal of Health, Medicine and Nursing

ISSN 2520-4025 (Online)

Vol.7, Issue 3. No.2, pp 10- 28, 2021

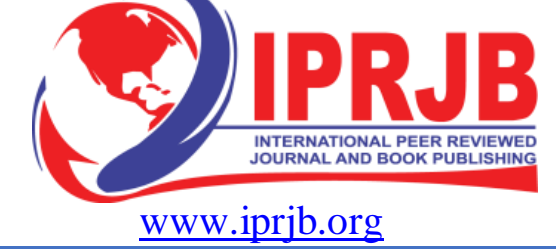

Mean values denoted by similar letters are not significantly different at $\mathrm{P} \leq 0.05$. Mean separation using Tukeys HSD

\subsubsection{Influence of the source of advice on delivery at home}

Advice on the individual place to deliver had a slight effect on the decision on where to deliver. Respondents who were advised by mothers-in-law (310 of the respondents) experienced a high number of deliveries at home (mean 2.65 children) than those getting advice from other relatives. This shows the influence of the mother in-laws in delivery decision-making. Table 4.11.

Table 11: Number of children delivered at home by respondents advised by different sources

\begin{tabular}{|c|c|c|c|c|c|}
\hline Source of Advice & & $\begin{array}{l}\text { No. of women } \\
\text { advised }\end{array}$ & $\begin{array}{l}\text { Number of children } \\
(\text { Mean } \pm \text { SE })\end{array}$ & Minimum & Maximum \\
\hline Spouse & & 139 & $2.04 \pm 0.05$ & 1 & 3 \\
\hline Mother in law & & 310 & $2.65 \pm 0.07$ & 1 & 9 \\
\hline $\begin{array}{l}\text { Traditional } \\
\text { attendants }\end{array}$ & birth & 287 & $2.43 \pm 0.05$ & 1 & 4 \\
\hline Self & & 258 & $2.39 \pm 0.05$ & 1 & 4 \\
\hline Extended family & & 300 & $2.56 \pm 0.06$ & 1 & 9 \\
\hline
\end{tabular}

\subsubsection{Influence of distance to the health facility on delivery at home}

Using Pearson correlation analysis, the findings revealed that the distance to health facility significantly influence women giving birth at home $(\mathrm{r}=0.534, \mathrm{P}=0.0001)$. Women who were staying far away from health facilities gave birth at home compared to those near the facility.

\subsection{SUMMARY, CONCLUSIONS AND RECOMMENDATIONS}

\section{Summary}

The mean age of the respondents was 34.0 years. In the united states, historically, births to older women have been more likely to be planned than births of younger mothers. Births to younger mothers and unmarried are less likely to be planned than older and married women (Hayford S, .2010). In 2013, Sub-Saharan Africa had the highest prevalence of young women who were pregnant, 101 per 1000 which translated to high number of non- hospital delivery, this is almost double the global average, some of this countries include, Uganda, Nigeria, Mozambique, Cameroon and Malawi. (Gunawardena et al.,2019). The level of education plays a major role in determining the place of delivery. In developed countries studies have noted that women enter into their first union late due to the many years they take when going through the formal education system which leads to delayed first birth. Women who are married off when they are young are likely not to plan for the first pregnancy and even on the place of giving birth. Married couples are expected to enjoy spousal support which would suggest that married women are more likely to give birth at a health facility

On the source of income, rustic women are mostly housewives and depend on close family members for financial assistance. Few involve themselves in small businesses such as having small shops in their homesteads and selling second-hand clothes during market days in the nearby shopping center. Immovable valuable assets like shops at the shopping center are owned by men and their wives had no power over them. Women also engage in minimal scale farming like rearing chicken and selling eggs locally. Cows, goats, and sheep belong to the men, and 
Journal of Health, Medicine and Nursing

ISSN 2520-4025 (Online)

Vol.7, Issue 3. No.2, pp 10- 28, 2021

women had no authority over them too.(WHO 2007).Women from pastoralists communities are involved in cattle and other domestic animal keeping which involves moving from one area to another and looking for greener pastures. Still, at the same time, they have no power to sell any animal for hospital bills. In conclusion, as far as the source of income is concerned, the Maasai women are primarily found in the informal sector. This has most likely added to their low social and financial status. The way of life of these people is another strong factor that has been found to influence the high chances of a woman having a delivery at home. (Njuguna et al., 2017).Home delivery is considerably cheaper than hospital delivery. Delivering at home with the help of a TBA, respondents proclaimed that they could contribute any payment - which could assist save money.

During antenatal care visits women are taught on how to plan for births and have back-up plans, many do not have any backup plans for life-threatening occurrences when giving birth. From other findings, few would deliver at home again and would not have any backup plan, while the majority would not deliver at home again and have a backup plan. This does not contradict a study by (Phiri et al., 2014), which suggested that chances of having a second and third delivery at home are higher than the first one due to lack of preparedness during pregnancy. (Kitui et al 2013) also in his study he noted that women with a higher parity generally tend not to plan for hospital delivery during pregnancy. In pastrolistic rural communities, the main reasons given as to why they would give birth again at home were. It is shame being naked in front of health workers and they have been circumcised. The husband and other relatives will not allow her, cultural beliefs and practices about births will be respected at home. Women who deliver at home are perceived to be courageous, and those who deliver in health facilities are weak. They value TBAs that they also know how to conduct deliveries, easily available, cheap and they observe cultural practices, and lastly is the association of illness and health facilities.(Amu $\mathrm{H}$ et $a l, .2016)$ For those who were not willing to deliver at home again, the main reason was that they had terrible experiences during delivery at home they cannot repeat again. (Moyer et al,.2016).

During ANC visits in a health facility women should certainly be able to plan together with the midwifes on place of delivery putting into consideration things like the distance from the woman's home to a health facility, who will be there to support the woman during labor and child birth and when to visit a health facility (Oni et al,.2012). Many women of Narok south subcounty are conversant with the risk factors of delivering at home. Bleeding, fistula and perineal tears are what many women knew and the most typical experiences they have had when deliveries happen outside a health facility. Giving birth at home without the assistance of a professional health care provider poses a much higher risk of obstetric emergencies and even loss of a woman's life and that of the baby.

Proficiency about difficulties when giving birth has been picked out as a prognosticator of health facility delivery in the event problems arise. In most studies participants who were well informed about the drawbacks during delivery were four times more likely to go through health facility delivery than women who do not have the appropriate information. Knowledge about impediments escalates with increasing maternal age but is substantially less so in mothers more than 35 years. Knowledge deficit on the effects of giving birth at home and its following consequences contributed to mothers, predominantly those who are multiparas, to deliver at home. Unmindful of health complications and societal problems related with giving birth at homeimparcted ongiving birth at home in primigravida women . (Kruk,et al,.2010) 
Journal of Health, Medicine and Nursing

ISSN 2520-4025 (Online)

Vol.7, Issue 3. No.2, pp 10- 28, 2021

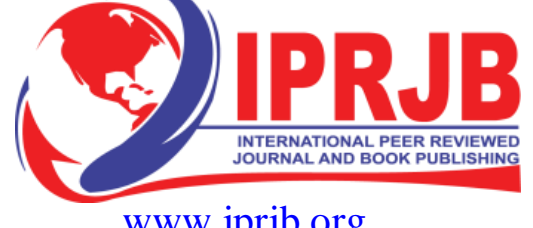

WWW.iprjb.org

Emergencies during delivery are well handled in a hospital setup and will greatly improve delivery outcome, the health of the mother and baby. (Moindi et al 2016).In a discovery in Ghana ,women who attended antenatal care received the critical care given during the antenatal visits at a higher percentage than those who did not, they received vaccination, were taught about HIV/AIDS, received information about birth preparedness and found health workers who answered there queries.(Gabrysch.et al,.2011).In contrast, most findings done in rural parts of Africa women who deliver at home don't receive quality care when they visit health facilities during pregnancy. Low uptake of antenatal care services could lead to higher chances of having a delivery at home. This also contradicts a study by (Chaunc, 2011) that most women do not receive quality services during ANC visits and that health care workers are not friendly as they deliver their services and have not had any discussion about birth preparedness. Health care providers play a significant tasking health education on the dangers of home birth, give health education on risks of home birth, and encourage hospital deliveries. (WHO 2015). In this study participants said that giving birth is not a disease that one should visit a health facility. Those mothers who indicated that they experienced complication during labor and delivery in their recent pregnancy were most likely going to utilize skilled services when giving birth. (Phiri et al., 2014). On the distance to the nearest health facility, majority in rural parts of Africa live between 80 to $200 \mathrm{kms}$, away from the nearest health facility. Only a handful live within 20 kilometers. This does tally with a study by (Titaley 2010) that most rural residents live far from health facilities. In Kenya, the Pokot community also are unable to access hospital delivery due to distance (Chauthary 2002). In Tanzania (Teplitskaya et al,.2018) also noted that $84 \%$ of those women who gave birth at home had organized to give birth in a health facility, but due to distance they could not.

The extended walking distance nearest health facility, the lesser the expectation of mothers to make use of skilled and trained delivery service. The absence of trouble-free transportation service to the nearest health facility is also an essential significant convolution. These findings are homogenous with the recommendations of studies carried out in Nepal, Zambia, and Ethiopia, wherein physical distance to maternity facilities and lack of geographic access were detailed as obstacles to place of delivery. (Amano.et al,.2012).

Source of information on reproductive health matters and more so about pregnancy, labor, and place of delivery can highly influence decision-making on the place of giving birth. Majority of women in rural areas receive advice on reproductive health matters from their 'mothers-in-law and extended family members. When pregnant mothers attend ANC they are taught about delivery and how to prepare for it. In a study done by (Mutiso 2008) 29.3\% of those women who went to ANC were never taught about labor and delivery, and $14.7 \%$ were never taught about the importance of hospital delivery and the dangers of non-facility births. Studies also report that women, especially from rural areas, seek and receive information on childbirth. from the mothers, mothers-in-law, TBAs, and spouses. (Campbell et al., 2016)

\section{Conclusion}

Regardless of the government effort to provide free maternal services in Kenya, stable source of income, formal education with the right knowledge about reproductive health and geographical access, are the determinants of place of delivery among women in rural parts of Narok County. This takes the relevant stakeholders, including the National government inter ministries, and Ministry of Health and sanitation, needs to be aware to these population tally in their decisions concerning reproductive health care in rural Kenya. Priorities to include citing health facilities 
Journal of Health, Medicine and Nursing

ISSN 2520-4025 (Online)

Vol.7, Issue 3. No.2, pp 10- 28, 2021

and public education on the need for health facility delivery. Distinct attention should be given to the poor, multiparous women and those with no or low levels of education.

\section{Recommendations}

The study recommends the County Education officers in liaison with social development officers to promote adult formal education to improve literacy levels, which will go a long way in influencing reproductive health decisions. The study also recommends the County health management team and the reproductive health section to network with other relevant stakeholders to increase sensitization on utilization of hospital-based deliveries. The Narok County Government should prioritize the addition of health facilities in the community. Health education by all relevant stakeholders on the advantages of hospital delivery is also key. County government department of health to create a complementary community-based approach of maternal health education through home visits that aim to decrease home-based deliveries and generate demand for facility-based deliveries. Establish community health units and train community health volunteers and traditional birth attendants to be safe motherhood promoters.

\section{REFERENCES}

Akilew, A., Tadesse, A., Leta, A., Bitew, D., Zeleke, M. (2014). Adverse birth outcomes among deliveries at Gondar University Hospital, Northwest Ethiopia. BMC pregnancy andchildbirth.(14),90-94.

Amegbor, M.(2014).health-seeking behavior in ASikuma-Odoben-Brakwa district: A pluralistic health perspective, master's thesis, University of Oslo Ghana. (1), 28- 35.

Amina, A., Susan, G.(2016).Investigating the debate of home birth safety; A critical review of cohort studies focusing on selected infant outcomes. Japan journal of nursing science/https;//doi.org/10.1111/jjns.12116.(1).60-64.

Atupamoi ,M. (2017). Factors influencing access to health care service in west Pokot county, Kenya. Master's thesis.(1), 13-14.

Baral ,R., Lyons, J., Teijligen, R.(2010).Determinants of skilled birth attendants for delivery in Nepal,faculty if applied social science.(8),325-328.

Bunyana, M. (2011). Women decision making and factors affecting their place of delivery; systematic review and qualitative study.PhD thesis, European institute of health and medicalsciences university of survey.(1),184-200.

Family care international (2012). A price too high to bear; The cost of maternal mortality to families and communities. FCI,(1),8-10.

Gary, J., Inacio, C., Wehrmeister, D., Barros, C., and Cesar, G. (2016). Inequalities in the coverage of place of delivery and skilled birth attendance: analysis of cross-sectional surveys in 80 low and middle-Income Countries.Reproductive Health(16). 13-77.

Graham, J., Bell, S., Bullough, H. (2001). Can skilled attendance at delivery reduce maternal mortality in developing countries? Safe motherhood strategies.(17),97-130.

Karanja, S., Gichuki, R., Igunza, P., Muhula, S., Ofware, P., Lesiamon, J., Leshore, L., Nyagero, J., Binkin, N., Ojokaa, D. (2018). Factors influencing deliveries at health facilities in a rural Maasai community in Magadi sub-county, Kenya. BMC pregnancy andchildbirth,(18),1-11. 
Journal of Health, Medicine and Nursing

ISSN 2520-4025 (Online)

Vol.7, Issue 3. No.2, pp 10- 28, 2021

Kenya Demographic Health Survey (2014).Kenya bureau of statistics(1),127-130.

Kingoo, B. (2015) Factors influencing attendance to antenatal care services in Kenya, the case of Somali women in Eastleigh in Nairobi county, Kenya. maters thesis university ofNairobi.(1),13-18.

Kitui, J., Lewis, S., Davey, G. (2013) Factors influencing place of delivery for women in Kenya; an analysis of the KDHS, 2008/2009. BMC pregnancy and childbirth (13),13-40.

Kwamena, D.,Adde, K., Amy, H. (2016). What influences where they give birth? Determinants of place of delivery among women in rural Ghana. Hindawi publishingcorporation (16), 8-10.

Luwei, P., debernis, L., shoo, R. (2009). maternal death review in Africa. international journal for gynecology and abstretrics.(106), 89-94.

Margolis, R., Mikko, M. (2015). parental wellbeing surrounding first birth as a determinant forfurther parity progression, Demography. (52), 1147-1166.

Ministry of Health (2012). Community midwifery services in Kenya. Ministryof healthreproductive health.(2),15-20.

MOH (2015). National adolescent sexual and RH policy -MOH-RH,(3), 9.

Moyer, A., Mustafa, A. (2013).Drivers and deterrents of facility delivery of delivery in sub Saharan Africa; A systematic review.Reproductive health 2013. (10).40-43.

Mrisho, M., Schellenberg, A., Moshi, K., Obrist B, Mshinda, H., Tanner, M., Schellenberg, D. (2017). Factors affecting home delivery in rural Tanzania. Tropical medicine internationalhealth.(12), 72-75.

Mutiso, M., Gureshi, T., Kinuthia, J. (2008). Birth preparedness among antennal clients at Kenyatta National Hospital. East Africa medical journal(6). 85-87.

Narok county government and European Union. keeping mothers and babies safe. Narokcounty government department of health records.(1),1-3.

Nganyo, P., Torud, K., Kvale, G., Byskor, J., Bjorg, E., Michelo, C., Echoka, E., Knut, F., (2014). Factors associated with health facility childbirth in districts of Kenya, Tanzania and Zambia: a population-based survey; BMC pregnancy and childbirth,(219), 14-21.

Nicholas, J., Kassebaum, B., Amelia, B., Megan, S., Coggeshall, C., Katya, S. (2014). Global, Regional and National levels and causes of maternal mortality during 1990-2013: A systematic analysis for the global burden of disease. The lancet 384 (9947, 9801004,2014.(1),80-84.

Njuguna, J., Njoroge, K., Muruka, C. (2017). Impact of free delivery policy on utilization of maternal health services in county referral hospitals in Kenya. BMC health serviceresearch(17),429-430.

Omondi, R., Ngari, M., Mbakaya, C.(2016) Why mothers still deliver at home; Understanding factors associated with home delivery and cultural practices in rural coastal Kenya. BMCPublic health(1) .1-5.

Otieno, O. (2015). Factors associated with home delivery in West Pokot County of Kenya, Advanced public health.(15),5-8. 
Journal of Health, Medicine and Nursing

ISSN 2520-4025 (Online)

Vol.7, Issue 3. No.2, pp 10- 28, 2021

Oweya, E., Koskei, N. (2008). safeguarding maternal and newborn health: Improving the quality of postnatal care in Kenya, International journal for quality in health care,(22),37-40.

Pathak, Singh, S.(2010).Inequalities in maternal health care;prenatal and skilled birth attendance in India.1992-2006. PloSONES5(10);e13593.doi;10.137/journal.pone.0013593 (1),5-7.

Phiri, N., Torrid, K., Kuale, G., Byskor, S., Michell, C., Echoka, E., Fylkesnes, K. (2014). Factors associated with health facility childbirth in districts of Kenya, Tanzania and Zambia: a population based survey. BMC pregnancy and childbirth, (14),219-221.

Qureshi, Z.(2008).Obstetrics in relation to millennium development goals. East African medical journal.(08),85-89.

Rajendra, K., Andy, H., Lee,B., Colin, W., Binns,K. (2013). Birth preparedness and skilled attendance at birth in Nepal: Implications for achieving millennium development goals 5. School of Public Health and Community medicine, BP Koivala Institute of Health Sciences, Dharama, Nepal.(I), 1206-1210.

Redshaw, M., Heikkila, K. (2010). Delivered with care: a national survey of women's experience of maternity care. The national perinatal epidemiology unit, University of Oxford,(1).29-34.

Saker, K., Rahman, T., Hossain, J., Reichenbach, L., Mitra, K.(2016). Reasons for preference of home delivery with TBAs in rural Bangladesh: A qualitative exploration pubmed.(2),810.

Saraladevi, N. (2009). Shortage of health care workers in developing Countries-Africa. Ethnicity and disease.(19),15-17.

Shiferaw, S., Spigt, M., Merijin, G., Yilma, M., Tekie M. (2013). why do women prefer home delivery in Ethiopia?BMC pregnancy and child birth, (.1), 86-90.

Sipsma, H., Thompson, J., Maurer, L., Bradley, E., Curry, 1. (2016). Preferences for home delivery in Ethiopia; provider perspective. Departmentof health policy and management Yaleschool of public health. (1),3-8.

Sonneveldt, E., Plosky, W., Storer, J. (2013). Linking high parity and maternal and child mortality; What is the impact of lower health services coverage among high order births? BMC public health.(13), 3-6.

Teplitskaya, L., Dutta, A., Pascal, T., Zetianyu, W. (2018). Maternal health services in Tanzania; Determinants of use and related financial barriers from 2015-2016 survey data Health policy plus.(1),8-11.

Titaley, R., Dibley, J., Roberts, L. (2012). Type of delivery attendant, Place of delivery and risk of early neonatal mortality; analysis of the 1994-2007 Indonesia demographic health survey. Health policy and planning.(27),405-416.

Turin, D. (2010). Health care utilization in the Kenyan health care system; challenges and opportunities. student pulse. (2),9-11.

Wanyua, S., Kaneko, S., Karama, M., Makokha, A., Ndemwa, M., Kisule, A., Changoma,K., Goto,K., Shimada, M., (2014). Role of traditional birth attendants and perception on the policy discouraging home delivery in coastal Kenya.BMC pregnancy and child birth (14). 1-2. 
Journal of Health, Medicine and Nursing

ISSN 2520-4025 (Online)

Vol.7, Issue 3. No.2, pp 10- 28, 2021

www.iprjb.org

WHO (2014). Trends in maternal mortality: 1990 to 2013 Estimates by WHO, UNICEF, UNFPA, World Bank \& UNPD, WHO library cataloguing -in- publication data,(1), 1421.

WHO (2017). An evidence map of Social, Behavioral and Community engagement interventions for reproductive, maternal, newborn and child health: WHO Community reproductive health. ISBN: 978-92-4-069726-(31), 90-98.

WHO, United Nations Population Fund, UNICEF. (2015). Pregnancy, childbirth, postpartum and newborn care.ISBN 978-92-4-154935-6. (1), 31-38.

World bank (2006). Trends in maternal health/health care in low income countries and implications on neonatal health.www.sfnjournal.com/articles/s1744165x(05)00080.(1),38-40.

Zohras, L., Jai, K., Rehana, A., Zulfiqar, A., Bhutt, S. (2014) Reproductive health 204.(2), 21-27.

Zxnevad, M., (2011). perception and practices related to home based and facility based birth. A qualitative study from Agemssa, Ethiopia, PHD Thesis, Centre for international health faculty of med and dentistry, University of Beigen, Norway,(1) 9-11. 